\title{
ENERGY AND RENEWABLE ENERGY USE IN EU28 AND HUNGARY ON THE BASIS OF STATISTICS
}

\author{
${ }^{1}$ Judit Csizmásné Tóth, ${ }^{2}$ Zsolt Hollósy, ${ }^{3} J u d i t$, Poór \\ ${ }^{1}$ Department of Economics, Finance and Accounting, Faculty of Economy, John von Neumann University, Tiszaligeti sétány 14, \\ 5000, Szolnok, Hungary, e-mail: judy.toth@gk.uni-pannon.hu \\ ${ }^{2}$ Department of Economic and Social Sciences and Rural Development, Georgikon Faculty, University of Pannonia, Deák F. Str. 16., \\ 8360 Keszthely, Hungary, email: hollosy@georgikon.hu \\ ${ }^{3}$ Department of Economic Methodology, Georgikon Faculty, University of Pannonia, Deák F. Str. 16., \\ 8360 Keszthely, Hungary, email: pj@georgikon.hu
}

\begin{abstract}
This paper presents the expansion of renewable energy sources of electricity generation over the last 10-15 years, based on statistical data for Hungary and for the EU-28 member states. The share of renewable energy in electricity production was almost $30 \%$ in the EU28 in 2016, while in Hungary it was only $7 \%$, which is the second lowest share in EU member states. In Hungary, the share of nuclear energy is still high in electricity production, and the proportion of biomass in renewable energy in Hungary is very high compared to the EU-28 average. An important issue for Hungary is how to reduce the share of nuclear energy in the longer term. Finally, the paper highlights the essential elements of the Hungarian METAR subsidy system aimed at encouraging the production of electricity (and heat) energy from renewable energy sources while minimizing the burden on end users.
\end{abstract}

Keywords: energy policy, renewable energy targets for shares of total energy and of electricity, gross domestic energy consumption, renewable energy use

\section{INTRODUCTION}

The people are increasingly aware of the need for renewable energy and energy efficiency to cover the increasing global energy demand (see Fig. 1) and to handle climate change, which creates new economic opportunities and can provide energy for billions of people who live without modern energy services. So the numbers of the countries with renewable energy policies and targets have grown dynamically over the past decade, and the statistics on renewable energy production also indicate a significant expansion.

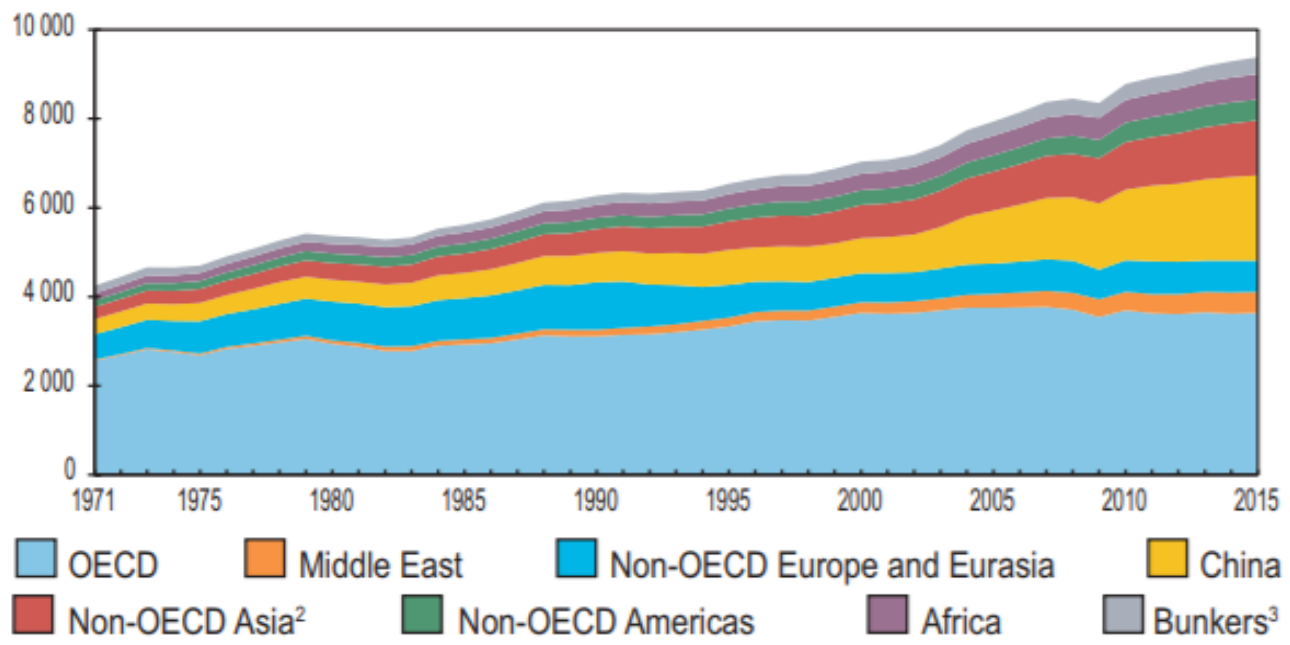

Figure 1. World total final energy consumption from 1971 to 2015 (Mtoe) Source: [1] 
The results of the implementation of a range of policies including targets, regulations, public financing and fiscal incentives are also reflected in the statistics of the world's energy production and consumption. According to the Global Status Report [2], 16.7\% of the world's primary energy was provided by renewable energy in 2004. Traditional biomass used mainly in remote rural areas in developing countries primarily for cooking and heating represented $9.0 \%$ and the share of large hydropower was $5.7 \%$. The socalled new renewables were $2.0 \%$ ( $0.2 \%$ biofuel, $0.7 \%$ hot water/heating, $1.2 \%$ power generation). The REN21 Global Status Reports have published the ratios for the final energy use since 2006, so we can compare the latest statistics back to 2006. At that time, a decade ago, the renewable energy accounted for $18.0 \%$ of the total final energy consumption (TFEC) (traditional biomass: $13.0 \%$, large hydropower: $3.0 \%$, hot water/heating: $1.3 \%$, power generation: $0.8 \%$, biofuel $0.3 \%$ ) [3]. On the basis of the latest statistics (GSR, 2018) modern renewables (without traditional use of biomass the share of which was $7.8 \%$ of TFEC) accounted for $10.4 \%$ of TFEC, most of which (5.4\%) was generated by renewable electricity (the greatest portion (3.7\%) is of hydropower). The renewable thermal energy (biomass/solar/geothermal heat) accounted for $4.1 \%$ and it was followed by transport biofuels $(0.9 \%)$. So the combined renewable energy was $18,2 \%$ in TFEC in 2016.

The overall share of renewable energy seems to increase modestly over the past ten years but a significant rearrangement can be identified. While the average 10-year growth rate of the TFEC was $1.7 \%$, the rate of the traditional biomass was only $0.2 \%$. So the traditional use of biomass has grown but not to the extent as TFEC therefore the decline of its share in TFEC. Meanwhile some renewable sectors are characterized by tremendous growth, the average 10-year growth rate of modern renewables was $5.4 \%$.

According to the GSR [4] the supply of renewable electricity generation increased $56.6 \%$ in the period from 2007 to 2015 thanks to more attention of policy makers to renewable power generation. During this period the supply of modern renewable heat increased 20.5\%, and in 2015 modern bioenergy (excluding traditional biomass) accounted for the majority of renewable heat. As renewable heating and cooling so far received less attention despite accounted for $48 \%$ of TFEC in 2015 (Fig. 2) it can be identified as the "sleeping giant of renewable energy potential" similar to transport. Transport accounted for $32 \%$ of TFEC and the majority (more than 90\%) of global energy needs of the sector are still met by oil. The proportion of biofuels was around $8 \%$, while electricity accounted for only $1 \%$. Figure 2 represents the share of the sectors in TFEC and the role of renewable energy by sector. On the basis of Figure it can be seen that renewable electricity can be used for electricity consumption or even heating/cooling and transport.

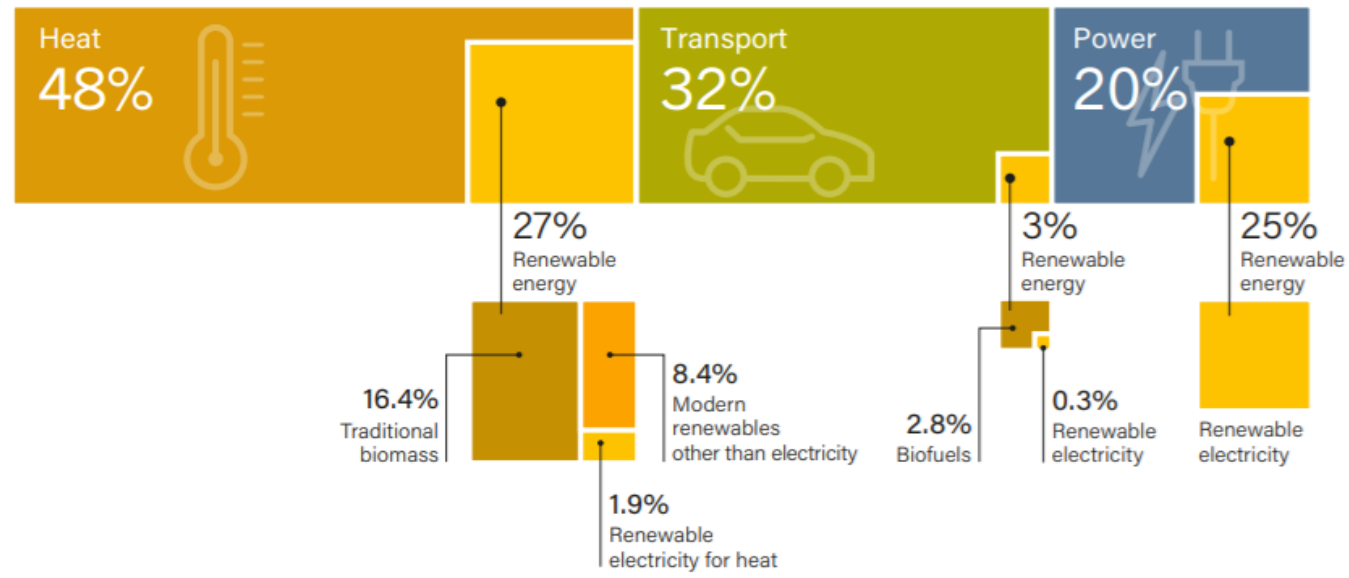

Figure 2. Renewable energy in TFC by sector, 2015 [4] 
Total renewable power capacity more than doubled in the last decade and it has the largest annual increase in 2017 thanks to primarily solar PV accounted for nearly 55\% of newly installed renewable power capacity. Global renewable power capacity supply $26.5 \%$ of global electricity with hydropower providing $16.4 \%$ and wind power accounting for $5.6 \%$.

\section{SHARE OF ELECTRICITY FROM RENEWABLE SOURCES IN THE EU MEMBER STATES}

The share of electricity from renewable sources in gross electricity consumption is very different between EU member states. More than three fifths of all the electricity consumed was generated from renewable energy sources - largely as a result of hydro power and solid biofuels — in Austria (72.6\%) and Sweden $(64.9 \%)$ while the share of electricity generated from renewables was more than $50 \%$ in Portugal $(54.1 \%)$, Denmark (53.7\%) and Latvia (51.3\%) (Fig. 3). In Cyprus, Hungary, Luxembourg and Malta the share of electricity came from renewable energy sources was less than $10 \%$ (Fig. 3).

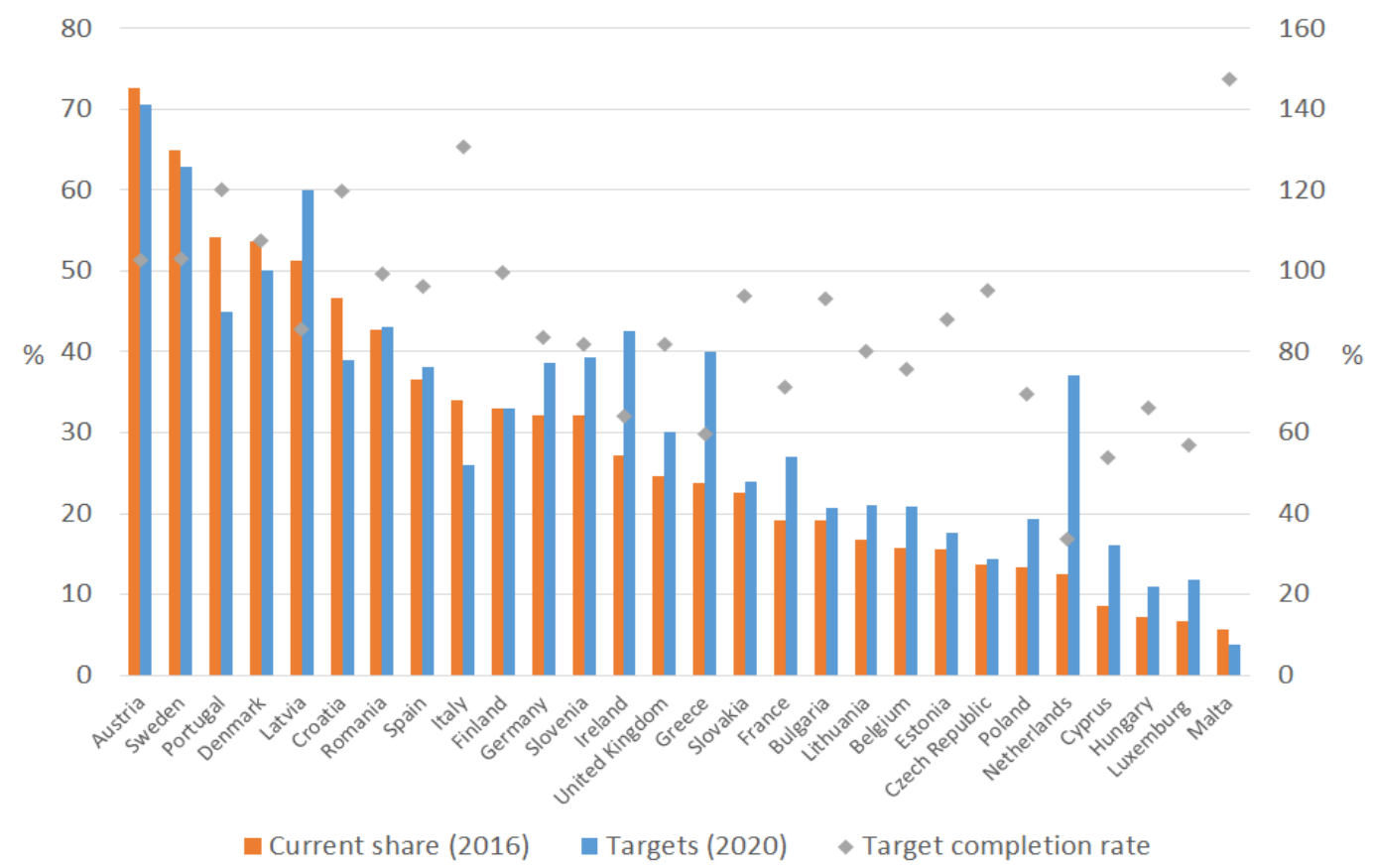

Figure 3. Targets and share of electricity from renewable sources in EU-28 Source: On the basis of EUROSTAT, own edition

In 2016, electricity generation from renewable sources contributed $30 \%$ to total EU-28 gross electricity consumption (Fig. 4). 


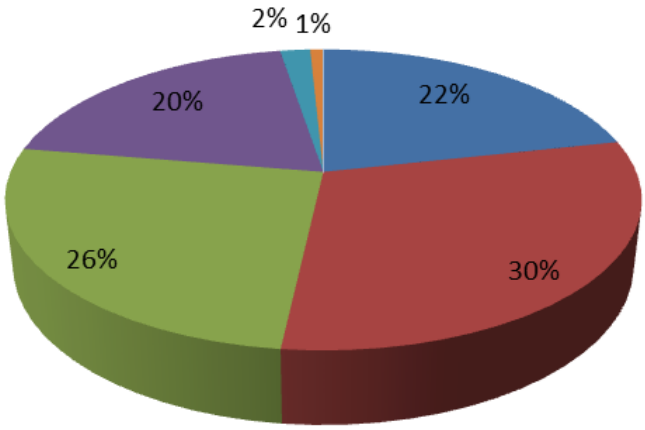

Solid Fuels

- Renewables

nuclear

Gases

Petroleum an Products

Wastes non-RES

Figure 4. Gross electricity generation by fuel in EU-28 (2016) [5]

During the period 1990 to 2016 the electricity generated in the EU-28 from renewable energy sources rose from $13 \%$ to $30 \%$ (Fig. 5). The growth in electricity generated from renewable energy sources largely reflects an expansion in three renewable energy sources across the EU, principally wind power, but also solar power and solid biofuels (including renewable wastes).

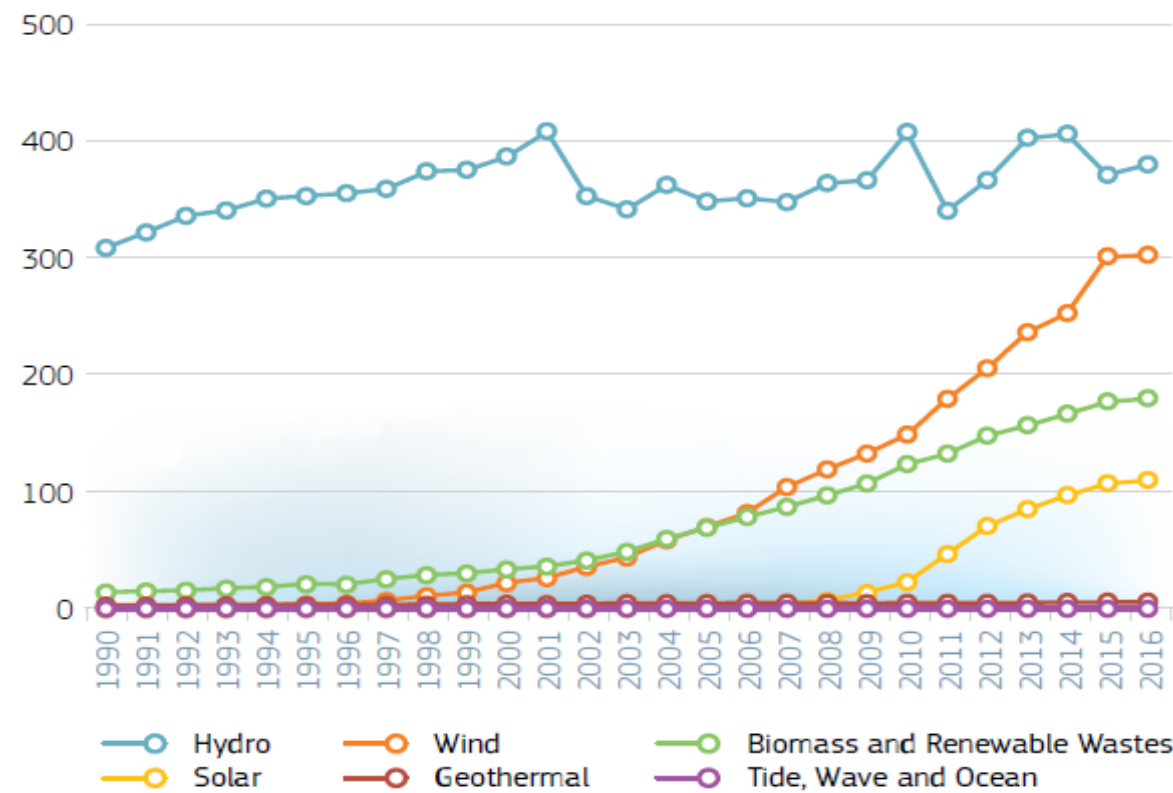

Figure 5. Renewables from gross electricity generation in EU-28 (1990-2016) [5]

Hydro power was the most important source for renewable electricity generation in the EU-28 in 2016 $(37 \%)$, followed closely by wind power (32\%) biomass (18\%), and solar power (12\%) (Fig. 6). 


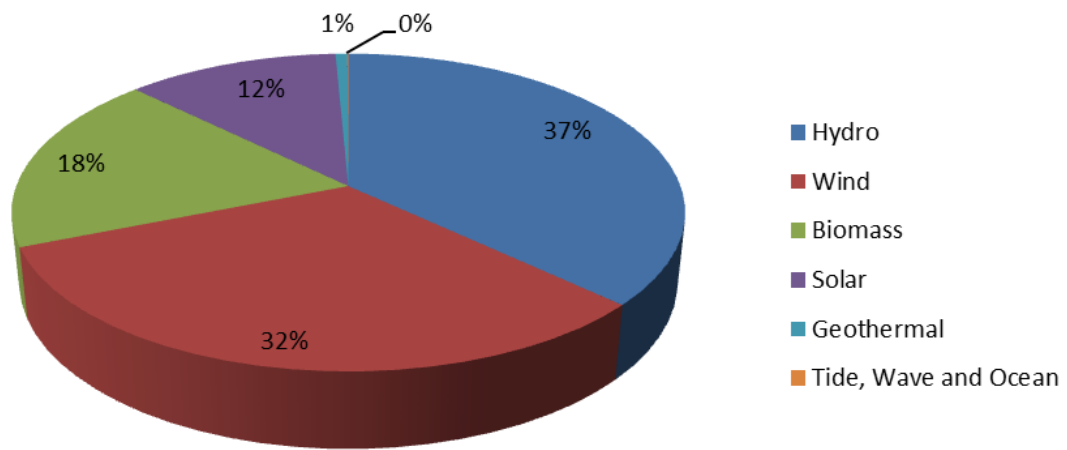

Figure 6. Renewables from gross electricity generation in EU-28 (2016) [5]

\title{
3. SHARE OF ELECTRICITY FROM RENEWABLE SOURCES IN HUNGARY
}

The share of Hungary is significantly different from the shares of the European Union. While in the European Union $30 \%$ of all the electricity consumed was generated from renewable energy sources, only $7 \%$ in Hungary which was the second lowest share in the EU.

The share of nuclear power (52\%) is very high in electricity generation (Fig. 7). According to nuclear strategy Hungary aims to maintain nuclear capacity over the long term, that is reconstruct new units parallel with the uprate and lifetime extension of the existing units. [6]

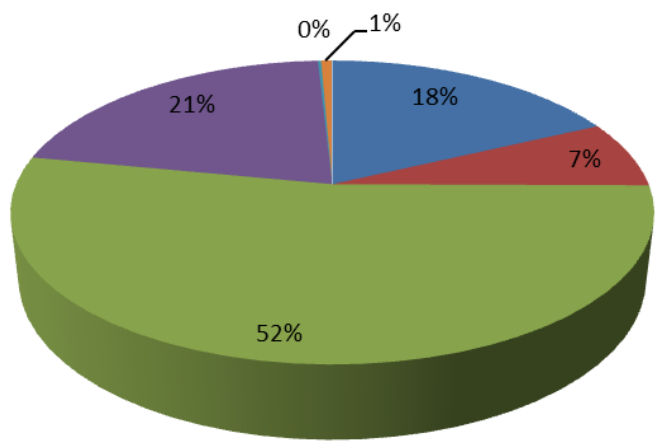

\author{
- Solid Fuels \\ - Renewables \\ - Nuclear \\ - Gases \\ - Petroleum an Products \\ Wastes non-RES
}

Figure 7. Gross electricity generation by fuel in EU-28 (2016) [5]

On the basis of the latest statistics in Hungary $65 \%$ of renewable electricity generation was generated by biomass, $21 \%$ by wind, $8 \%$ by hydro power and by $6 \%$ by solar energy [5].

In Hungary, the share of renewables in TFEC shows a significant increase since 2005 (Fig. 8). In 2016 the rate of renewables was $14.19 \%$. Although this exceeds the $13 \%$ target set by the Renewable Energy Directive as a mandatory target of 2020 , however, the most of this is provided by biomass, which is a renewable energy source but more than questionable whether it can be called clean. 


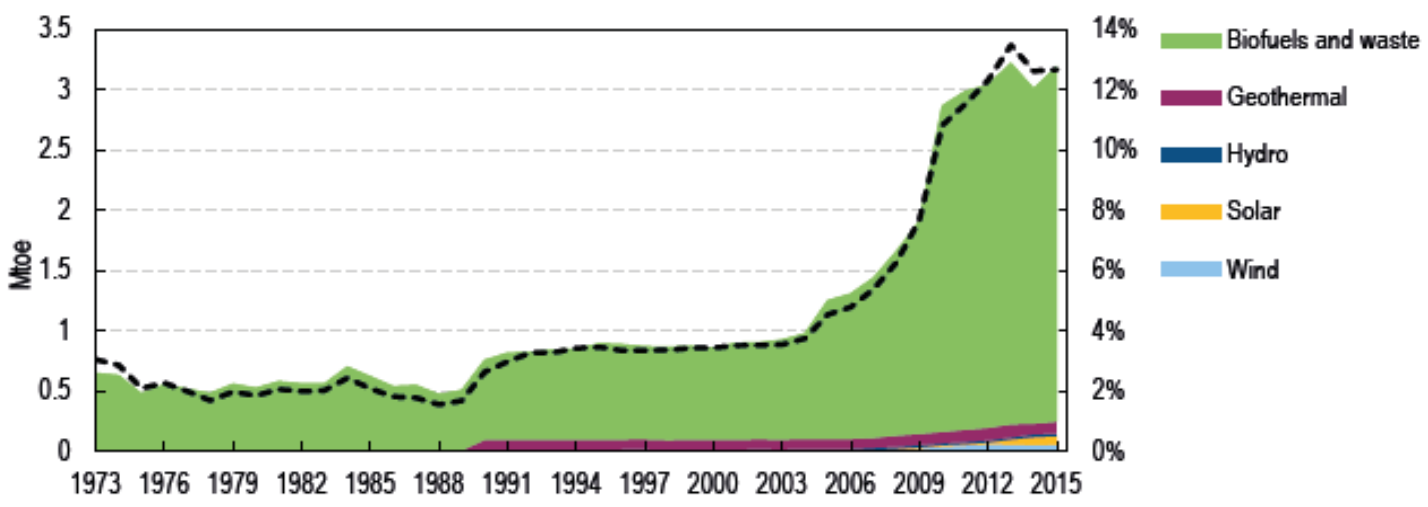

Figure 8. Renewables energy in Hungary as a percentage of TPES (1973-2015) [6]

\section{METÁR SUPPORT SYSTEM IN HUNGARY}

In Hungary in 2017, a new operational support system (METÁR) was introduced for renewables-based electricity generation. The previous support system (KÁT) continues to operate for existing plants following the introduction of METÁR, however, only new entrants will be eligible for the METÁR support mechanism. This new mechanism facilitates the integration of renewable electricity producers into the market, and supports the fulfillment of Hungary's 2020 renewable energy targets [6].

METAR subsidies can be granted for electricity generation that is linked to a new investment. Existing power plant units may also be eligible for support that will undergo major renovations or upgrades, with a cost exceeding $50 \%$ of the original initial investment cost. Combustible or waste incineration plants can only receive support (renewable energy proportionate) for renewable energy sources [7].

METÁR will also introduce a brown premium for depreciated biomass and biogas power producers to avoid the shutdown of these plants or the switch to fossil fuels in depreciated plants. METÁR contains strong guarantees regarding the usage of wood as fuel for electricity generation in order to prevent illegal logging and to protect forests [6].

\section{ACKNOWLEDGEMENT}

This research is supported by EFOP-3.6.1-16-2016-00006 "The development and enhancement of the research potential at John von Neumann University" and EFOP-3.6.1-16-2016-00015 (financial support of Széchenyi 2020) project. Projects are supported by the Hungarian Government and co-financed by the European Social Fund.

\section{REFERENCES}

[1] International Energy Agency (IEA) (2017): Key world energy statistics.

[2] Global Status Report (GSR): Renewables Global Status Report 2005. Renewable Energy Policy Network for the 21st Century - REN21

[3] Global Status Report (GSR): Renewables Global Status Report 2007. Renewable Energy Policy Network for the 21st Century - REN21

[4] Global Status Report (GSR): Renewables Global Status Report 2018. Renewable Energy Policy Network for the 21st Century - REN21

[5] EU Energy In Figures, Statistical Pocketbook 2018, European Union, 2018.

[6] Energy Policies Of IEA Countries - Hungary 2017 Review, OECD/International Energy Agency, 2017.

[7] http://www.mnnsz.hu/megujulo-tamogatasi-rendszer-metar/, date of download: 2018.10.10. 